Full length article

\title{
Laser-assisted fabrication and in vitro verification of functionalized surface for cells biointegration
}

\author{
Vadim Veiko $^{\text {a, }}$ Yulia Karlagina ${ }^{\text {a, }}$, Tatiana Itina ${ }^{\mathrm{a}, \mathrm{b}}$, Daria Kuznetsova ${ }^{\mathrm{c}}$, Vadim Elagin ${ }^{\mathrm{c}}$, \\ Elena Zagaynova $^{c}$, Gennady Chernenko ${ }^{\mathrm{d}}$, Elena Egorova ${ }^{a}$, Catherine Zernitskaia ${ }^{\mathrm{e}}$, \\ Sergey Manokhin ${ }^{\mathrm{f}}$, Anastasia Tokmacheva-Kolobova ${ }^{\mathrm{g}}$, Galina Odintsova ${ }^{\mathrm{a}}$ \\ ${ }^{a}$ ITMO University, 197101 Saint-Petersburg, Russia \\ ${ }^{\mathrm{b}}$ Laboratoire Hubert Curien, UMR CNRS 5516/UJM-Saint-Etienne/Univ. Lyon, 42000 Saint-Etienne, France \\ ${ }^{\mathrm{c}}$ Institute of Biomedical Technologies, Privolzhsky Research Medical University, 603005 Nizhny Novgorod, Russia \\ ${ }^{d}$ Lenmiriot Dental Implant Prosthetics Manufacture, 193079 Saint-Petersburg, Russia \\ ${ }^{\text {e }}$ Pavlov First Saint Petersburg State Medical University, 197022 Saint-Petersburg, Russia \\ ${ }_{\mathrm{f}}^{\mathrm{f}}$ Institute of Problems of Chemical Physics (IPCP), Russian Academy of Sciences, 142432 Chernogolovka, Moscow, Russia \\ ${ }^{\mathrm{g}}$ Belgorod National Research University, 308015 Belgorod, Russia
}

\section{A R T I C L E I N F O}

\section{Keywords:}

Titanium implants

Laser structuring

Relief

hMSCs

Biocompatibility

Osteogenic differentiation

\begin{abstract}
A B S T R A C T
The paper investigates how the surface relief of an implant affects cell behavior. Currently, most implant manufacturers claim the key impact biocompatibility factor to be surface micro-roughness. We suppose that the interaction between cells and implants also depends on such relief peculiarities as continuous or discontinuous topography, subcellular distance between peaks and presence of porous oxide layer. We have developed the laser processing conditions that provide three different reliefs: «open grooves», «grid» and «close grooves». Along with the micro-roughness characteristics the reliefs differ with their deepness and period of grooves. The surface composition analysis results have shown a sandwich structure consisting of $\mathrm{Ti} \rightarrow \mathrm{TiO} \rightarrow \mathrm{Ti}_{2} \mathrm{O}_{3} \mathrm{Nx}_{\rightarrow} \mathrm{TiO}_{2}$ (anatase) $\rightarrow \mathrm{TiO}_{2}$ (rutile). The wettability study has demonstrated superhydrophilicity (CA is $0^{\circ}$ ) for all reliefs. The quantitative and qualitative analysis of hMSCs proliferation and osteogenic differentiation was performed for 20 days. In vitro study has revealed the topography affects the spatial orientation of cells. The shape and size of the cell nuclei vary with different topographies. We have found continuous «open grooves» structures with the subcellular to cellular period are beneficial for cells' life-sustaining activity. Discontinuous «grid» structures with individual slots might not provide cells with mobility with the least external mechanical effect compared to «open grooves».
\end{abstract}

\section{Introduction}

The survival of dental implants is closely related to the long and painful period of postsurgical repair of surrounding tissues. Despite the relatively low failure rate of within $5 \%$ at 10 years or more of followupped implants [1], those who reject an implant have to restore lost bone tissue, fix a new implant and undergo a lengthy healing period, which may take from 3 to 6 months, following doctors' prescriptions. Thus, today the problem of implant survival remains relevant. The survival rate and long-term functioning of installed implants are affected by the quality of the implantation, oral hygiene during implant exploitation, as well as the characteristics of the implant itself, namely, material, shape and structure of the surface [2]. Surgery process and oral hygiene depend on the dental surgeon's qualification and the patient's responsibility, respectively, but the surface characteristics enhancement is accessible to implant manufacturers. It was shown that surface relief, roughness, wettability and chemical composition of titanium implant surface are crucial points for its biocompatibility [3-9]. To change the relief and chemical composition, sandblasting methods, chemical etching and their combination [10-13], anodizing [14-18] and laser structuring [19-26] are the most frequently applied. Sandblasting allows to obtain a disordered developed relief by bombarding the surface with a powder jet directed under pressure. Usually, acid etching of the treated surface follows sandblasting to smooth some sharp peaks, but, as

\footnotetext{
* Corresponding author at: Kronverksky Pr. 49, bldg. A, St. Petersburg 197101, Russia.

E-mail address: jujukarlagina@itmo.ru (Y. Karlagina).
} 
a recent study showed, $\mathrm{Al}_{2} \mathrm{O}_{3}$ particles still remain on the surface [27]. In the process of anodizing, by selecting the magnitude of electrical current and composition of an electrolyte, a porous relief with a pore size of $\leq 8 \mu \mathrm{m}$ is formed on the titanium surface [28,29]. Using the laser structuring with various processing modes and scanning patterns, it is possible to create a wide range of various reliefs: grooves [24,25,30-33], grids and craters [19,26,34], biomimetic microcones [35], nanoreliefs [36], etc. The width, depth, and period of laser-induced microstructures usually vary from units to hundreds of micrometers. Noteworthy, laser machining reduces surface contamination [37]. The formation of microand nanorelief in the process of anodizing and laser structuring is accompanied by various surface modifications of titanium oxide: $\mathrm{TiO}_{2}$ (rutile and anatase), $\mathrm{Ti}_{2} \mathrm{O}_{3}$, TiN. The height of the oxide layer reaches from a few nanometers to several microns [28,29]. Titanium oxides increase the corrosion resistance of the implant [7].

The methods mentioned above are applied in the industrial production of dental implants. In this case the most commonly used parameters for surface characterization are usually a height-descriptive parameter average surface roughness (Sa) (the arithmetic mean deviation of a surface) and hybrid parameter spell out (Sdr) (the ratio between the area of the "real" developed surface and the area of the "projected" surface [38]). Roughness of different implant zones depends on implant manufacture: Sa from $0.13 \mu \mathrm{m}$ to $1.49 \mu \mathrm{m}$ and Sdr from $1.7 \%$ to $172.7 \%$ (Nobel Biocare AB, Göteborg, Sweden) [28]; Sa from $1.78 \mu \mathrm{m}$ to $2.1 \mu \mathrm{m}$ (Institut Straumann AG, Basel, Switzerland) [39,40]; Sa from $1.1 \mu \mathrm{m}$ (Astra Tech Dental AB, Mölndal, Sweden) [34]; Sa from $0.3 \mu \mathrm{m}$ to 0.68 $\mu \mathrm{m}$ (Biomet, Palm Beach Gardens Fl, USA) [41]. According to the review [42] the authors conclude the "optimal" range is from $1 \mu \mathrm{m}$ to $2 \mu \mathrm{m}$, based on the studies where Sa range from 0.6 to $11.0 \mu \mathrm{m}$ was analyzed. On the other hand, very rough surfaces may leave such a distance between peaks that cells perceive them as smooth surfaces. However, there are works in which Sa's surface about $9 \mu \mathrm{m}$ indicates high biocompatibility for bone regeneration of titanium implants [43]. As was shown by computerized simulation in [44], the lateral resolution of an instrument/method of surface roughness estimation significantly limits measurements' accuracy.

We hypothesized that roughness Sa significantly exceeding $2 \mu \mathrm{m}$ can also give a positive bone response if the distance between peaks is considered. The research for the neural stem cells (NSCs) demonstrated that the type of topography, continuous or discontinuous, the size of single elements of relief and their relative position affect the spatial orientation of NSCs $[45,46]$. It was also shown that alternating grooves (continuous topography) with subcellular and cellular width strongly promote neurite guidance and orientation along the grooves. Discontinuous topographies with subcellular to cellular scales influence different lineage differentiation.

However, the question remains, whether the cells-implants interaction between cells and implant surfaces is affected not only by surface micro-roughness (parameters $\mathrm{Ra} / \mathrm{Sa}, \mathrm{Sdr}$, etc.), as most implant manufacturers claim, but also by the relief, which includes continuous or discontinuous topography, the subcellular distance between peaks (or period of the microstructure) and the presence of nanoparticles. We suppose such a complex surface structure is justified for several reasons. To fix cells to the surface, they need a relatively rigid but hydrophilic base. For a long-life span and reproduction (proliferation) on the surface, they need oxygen for breathing, heat and ventilation for removing waste products, as well as conditions for sleep and rest - suppleness (softness) of a substrate and its ventilation. To remove waste products, hydrophobic channels are necessary. Today, a comprehensive study that considers both the technological aspects of creating such a surface for titanium implants and preclinical study of their effectiveness is required. This work aims to verify the hypothesis which states that bone cells need not only a rough surface for fixing but also a special relief to provide the comfortable life-sustaining activity of cells throughout their lives.

We have conducted an in vitro study for human bone marrow mesenchymal stem cells (hMSCs). By laser processing, we developed three different reliefs with the subcellular and cellular period of microstructures (tens of microns) that enable certain mobility of cells along with the least external mechanical affect. Two types of continuous reliefs, «open grooves» OG and «close grooves» CG, and discontinuous relief, «grid» G, were fabricated on 6Al4V-titanium surface. To increase cell - surface connection area, groove and grid sidewalls were made rough. We have investigated the cellular activity on these reliefs and compared them with each other and with an untreated smooth surface.

\section{Material and methods}

\subsection{Surface relief engineering and investigation}

Titanium alloy Ti-6A1-4V discs ( $1 \mathrm{~mm}$ thickness, $5 \mathrm{~mm}$ diameter) and flat plates (with dimensions $5 \times 5 \mathrm{~cm}$ ) were filed down with 100-2000 grid sandpapers and polished to the mirror-like surface $(\mathrm{Ra}=$ $0.6 \pm 0.02 \mu \mathrm{m}$, measured on profilometer Hommel Tester T8000) with diamond paste $(\mathrm{Ra}=0.5 \mu \mathrm{m}$ and $0.1 \mu \mathrm{m})$ using a Dremel mini drill. Samples were cleaned from contaminations in an ultrasonic bath filled with distilled water, acetone and isopropanol consequently. After that, the samples were stored under normal ambient air conditions.

Fabrication procedures. The surface of the titanium alloy disks was processed by the ytterbium pulsed fiber laser. The laser wavelength was $1064 \mathrm{~nm}$, the average laser power was $1-20 \mathrm{~W}$, the pulse duration was $100 \mathrm{~ns}$, and the repetition rate was $10-100 \mathrm{kHz}$. In our experiments, laser radiation was focused in the spot of $50 \mu \mathrm{m}$, the focal length is 184 $\mathrm{mm}, \mathrm{M}^{2}$ is 1.99 . No assist gas was used during the experiments to control the degree of oxidation during the processing. Laser processing was performed in the air under normal conditions. Line-by-line scanning of the disk surface was performed with overlapping laser pulses along the $\mathrm{X}$-axis with the step of $\mathrm{M}_{\mathrm{x}}$ and the $\mathrm{Y}$-axis with the step of $\mathrm{M}_{\mathrm{y}}$ (Fig. 1).

Laser processing conditions of all reliefs are summarized in Table 1 , where $P$ - average power, $\mathrm{f}$ - pulse repetition frequency, $v$ - scanning speed, $N$ - number of loops, $I$ - intensity (calculated as the ratio of the peak power to the cross-sectional area of the laser beam waist), $\mathrm{Mx}-\mathrm{X}$ axis overlapping, $\mathrm{My}-\mathrm{Y}$-axis overlapping. These laser processing conditions provide heating the titanium surface above the evaporation threshold.

CG relief is formed under laser exposure modes below the evaporation threshold, on the other hand, G and OG reliefs are formed above the evaporation threshold. During the first pass of laser radiation on the surface of all samples (when it is heated above the melting point), a molten pool is formed and under the pressure of recoil vapors the material is ejected with the formation of rolls along the edges. Heating the metal above the evaporation threshold (for G and OG reliefs) promotes more intense evaporation and increase in groove depth. So, we form massive groves by removing current grove relative to the previous one on value My.

To form the G and CG reliefs, the second pass of laser radiation is

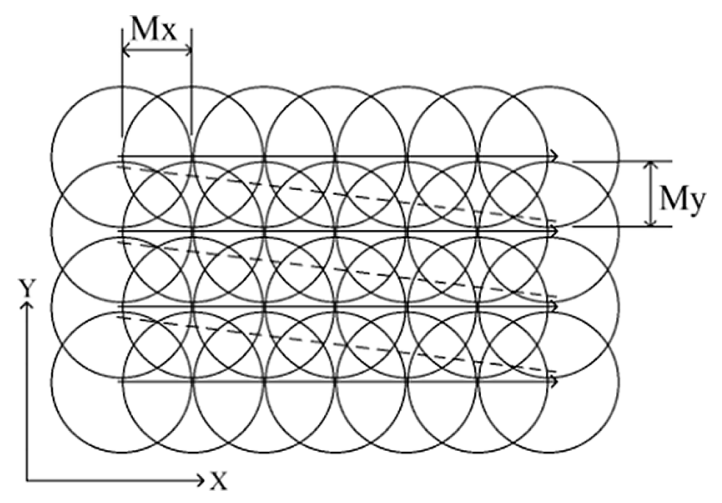

Fig. 1. Overlapping of laser pulses along the $\mathrm{x}$-axis Mx and along the $\mathrm{y}$-axis My. 
Table 1

Laser processing conditions for the «open grooves» OG, «grid» G and «close grooves» CG reliefs.

\begin{tabular}{llllllll}
\hline Relief & $P, \mathrm{~W}$ & $\begin{array}{l}f, \\
\mathrm{kHz}\end{array}$ & $\begin{array}{l}v, \mathrm{~mm} / \\
\mathrm{s}\end{array}$ & $\begin{array}{l}N, \text { line/ } \\
\mathrm{mm}\end{array}$ & $\begin{array}{l}I, \mathrm{~W} / \\
\mathrm{cm} 2\end{array}$ & $\begin{array}{l}M x, \\
\mu \mathrm{m}\end{array}$ & $\begin{array}{l}M y, \\
\mu \mathrm{m}\end{array}$ \\
\hline OG & 3.00 & 1.6 & 5 & 11 & $5.7 \cdot 10^{7}$ & 3 & 90 \\
G & 8.18 & 60 & 200 & 20 & $5.7 \cdot 10^{7}$ & 3 & 40 \\
CG & 2.65 & 20 & 15 & 30 & $2.7 \cdot 10^{7}$ & 3 & 40 \\
\hline
\end{tabular}

carried out in the orthogonal direction in relation to the first pass with the same laser parameters.

For CG relief formation the grooves from the first pass almost remelt (without deep channel formation). After the second pass (in the orthogonal direction) the narrow grooves are obtained by repeated laser exposure. When the second pass of $\mathrm{G}$ relief formation, the same grooves are formed in the orthogonal direction. Deep slots are formed at the center's intersection of two orthogonal grooves.

To form OG relief, the second and the third passes of laser radiation is carried out in the parallel direction with a step of My value relative to the previous pass.

The diagrams of scanning patterns for G, CG and OG reliefs are presented in Fig. 2.

A total of 36 disk-shaped samples and 12 flat square plates with laserinduced structures were fabricated. To test the repeatability of the structures 5 random samples for every structure were selected, then the standard deviation $(3-6 \mu \mathrm{m})$ was calculated.

Surface topographic analysis. Roughness measurements were performed on contact profilometer Hommel Tester T8000. The measurement area was $300 \times 300 \mu \mathrm{m}$. The resolution of the instrument is $100 \mathrm{~nm}$, the accuracy, according to DIN 4772 is Class 1. Measurement error is $\pm 1 \mu \mathrm{m}$. Surface roughness parameters such as Sa and Sdr were calculated. All areas were measured 3 times for each experimental sample to evaluate their stability and calculate standard deviation of the data.

Surface wettability. The measurements of the static contact angle (CA) were performed with a home-developed setup based on the LED arrangement source (summary power $1 \mathrm{~W}$ ) and high-resolution CCD camera ToupCam. The setup does not enable the measurement of the dynamic contact angles. Distilled water was used as a test liquid. An CCD camera was used with a sample rotation stage enabling $360^{\circ}$ contact angle measurements of the deposited droplet. A minimum of three droplets was analyzed in each condition to determine the contact angle values. The volume of the droplet was $0.5 \mu$. The CA was measured immediately following the laser treatment. The Digimizer software was used to measure the CA. Aging effect was not studied.

Scanning electron microscopy (SEM) analysis was performed using microscopes FEI Helios 660 (at electron and ion modes) and FEI Quanta 600 with field emission, equipped with an energy dispersive spectrometer (EDX) (EDX-analysis resolution is $0.20-0.25 \%$, elements from Be).

A field-enhanced emission microscope Tecnai G2 F20 equipped with an EDAX system for $\mathrm{x}$-ray microanalysis with a silicon drift detector was used to study nanosecond laser treatment's effect on the phase structural state of the near-surface layers of titanium alloy. The preparation of thin cross-section foils for TEM was conducted using focused ion beam (FIB)

\section{G, CG}

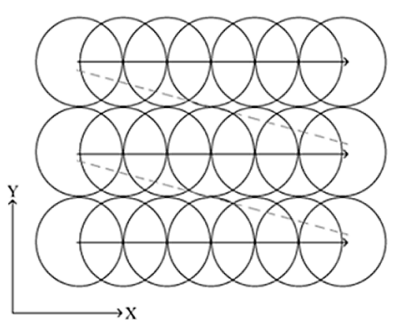

$1^{\text {st }}$ pass

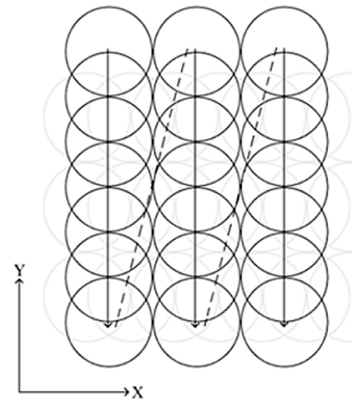

$2^{\text {nd }}$ pass

OG

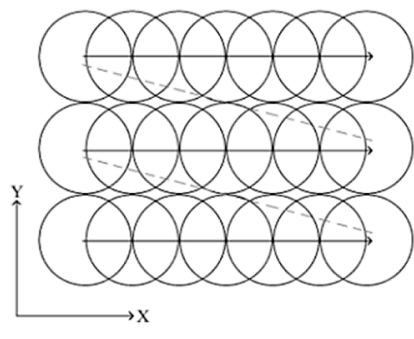

$1^{\text {st }}$ pass

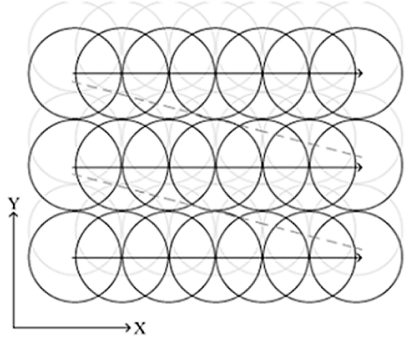

$2^{\text {nd }}$ pass

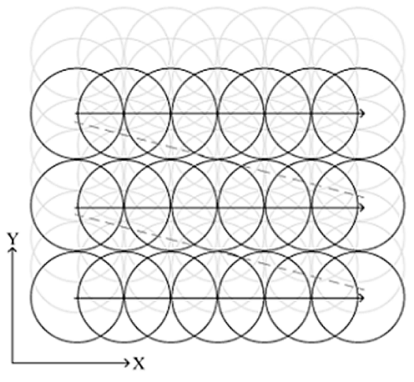

$3^{\text {rd }}$ pass

Fig. 2. Scanning patterns of G, CG and OG reliefs. 
of scanning electron-ion microscope FEI Helios 660. Platinum was used as a protective material for a region of interest and deposited using gas injector systems (GISs) integrated into a microscope camera. The sample with a thickness of about $100 \mathrm{~nm}$ and a region of interest of about $7.5 \times$ $7.5 \mu \mathrm{m}^{2}$ was prepared by gradual ion thinning and used for subsequent transmission electron microscopy (TEM) analysis.

\subsection{In vitro analysis}

We used human bone marrow mesenchymal stem cells (hMSCs) that were isolated from bone marrow of normal donors with their informed consent according to the institutional guidelines under the approved protocol described elsewhere [47]. The hMSCs were isolated and characterized by flow cytometry (Cell Lab Quanta SC, Beckman Coulter, USA) as described previously [47]. The common markers to human MSCs (CD34, CD45, HLA-DR, CD105, CD44, CD54, CD73, and CD90) were studied. The cells (indicated hMSCs-TurboFP635) were stably transfected with a gene of far-red fluorescent protein TurboFP635 (lentiviral transfer vector LVT-TurboFP635, Evrogen, Russia) according to the protocol also described in [47]. The cells were cultured in MesenCultTM MSC Basal Medium supplemented with MesenCultTM MSC Stimulatory Supplement (Stemcell Technologies, Canada) and $0.58 \mathrm{mg}$ / $\mathrm{ml} \mathrm{L-glutamine} \mathrm{(PanEco).} \mathrm{The} \mathrm{cell} \mathrm{culture} \mathrm{was} \mathrm{maintained} \mathrm{at} 310 \mathrm{~K}$ in a $5 \% \mathrm{CO}_{2}$ humidified atmosphere.

Titanium samples were placed on a 48-well plate, sterilized under UV light for $30 \mathrm{~min}$ and individually seeded $\left(5 \cdot 10^{4} \mathrm{hMSCs}\right.$-TurboFP635 per implant) with cells in the third passage. The cells were seeded on the samples with laser-modified surface in the same day as the ones were fabricated. The fluorescence of the hMSCs-TurboFP635 was detected using a Leica DM IL LED Fluo microscope equipped with TX2 filter cube (Germany). Fluorescence imaging was performed on days 1, 5, 10, 15 and 20 after cell seeding. To estimate the number of cells on the implants, we used a unique technique developed earlier for bone scaffolds and labeled cells. The details of the processing methodology can be found in [47].

On day 20 we analyzed the osteogenic differentiation of the seeded cells. We assessed osteocalcin expression in the cells and alkaline phosphatase (ALP) activity in a culture medium. Osteocalcin is the most abundant noncollagenous bone protein that constitutes $1-2 \%$ of the total matrix proteins. Osteocalcin is exclusively secreted by osteoblasts and recognized as an early marker of in vitro osteogenic differentiation of mesenchymal stem cells [48]. ALP is one of the most commonly used markers of mesenchymal stem cells' osteogenic differentiation in vitro. This metalloenzyme is an important component in hard tissue formation, highly expressed in mineralized tissue cells [49].

We performed immunocytochemical staining with the antiosteocalcin antibodies (Anti-Osteocalcin PicobandTM Antibody, Boster Biological Technology, USA). The immune complex was visualized using Opal 520 TSA Plus (Opal kit, Perkin-Elmer, Waltham, MA). The cell nuclei were stained with Hoechst 33,342 (Thermo Fisher Scientific, USA). The Opal 520 fluorescence signal was detected using a Leica DM IL LED Fluo microscope equipped with I3 filter cube. The Hoechst 33,342 was observed using an A4 filter cube (Germany).

To assess ALP activity, we conducted a fluorometric assay of culture medium harvested from the implants with cells (Alkaline Phosphatase Detection Kit, Fluorescence, Sigma, USA). The fluorometer (Synergy ${ }^{\mathrm{TM}}$ Mx Multi-Mode Microplate Reader, BioTek Instruments, Inc., USA) was set to $360 \mathrm{~nm}$ excitation and $440 \mathrm{~nm}$ emission. A medium with no secreted ALP was served as a negative control, which indicated the background level.

All staining procedures were done according to the standard protocols of Sigma, Thermo Fisher Scientific, Boster Biological Technology, Perkin-Elmer.

All in vitro experiments and experimental protocols were approved by the Research Ethics Board of the Nizhny Novgorod State Medical Academy (Privolzhsky Research Medical University, Nizhny Novgorod,
Russia) and obtained according to the principles of the Declaration of Helsinki.

\section{Results and discussion}

\subsection{Surface relief and wettability}

We have studied three different reliefs on the titanium surface by pulsed fiber laser: «open grooves» $O G$, «grid» G and «close grooves»CG. The choice of these three surface structures is based on the two-stage classification [46], including continuous and discontinuous topographies. In current investigation, we have developed laser processing conditions that provide the formation of well-ordered reliefs (Fig. 3) which consist of a microrelief on the walls of grooves and slots (Fig. 3B) to fix cells on the surface better and a porous oxide layer (Fig. 3C) for protein adhesion in the early stages of biointegration. The nanotopography on the surface of the reliefs is unintentionally produced. These features appear due to non-controllable processes - inverse precipitation of evaporated material from the surface that occurs during the laser treatment [50].

Using scanning electron microscopy, the structures' period was calculated. The period of the OG relief is $30.2 \pm 2.4 \mu \mathrm{m}$. The period of the $\mathrm{G}$ relief is $49.5 \pm 4.6 \mu \mathrm{m}$. The period of the CG relief is $31.4 \pm 3.3 \mu \mathrm{m}$.

Using contact profilometry height-descriptive Sa and hybrid Sdr parameters of untextured titanium and the reliefs surface were measured (Table 2). The roughness of Ti reference sample is $0.42 \mu \mathrm{m}$ (Sa) and $6.65 \%$ (Sdr). The roughness of «open grooves» is $3.85 \mu \mathrm{m}$ (Sa) and $46.57 \%$ (Sdr). The roughness of «grid» $11.81 \mu \mathrm{m}$ (Sa) and $272 \%$ (Sdr). The roughness of «close grooves» is $3.26 \mu \mathrm{m}$ and $43.08 \%$ (Sdr).

We obtained 3D surfaces (Fig. 4) of the samples' reliefs cross-sections (Fig. 4).

The initial surface of our samples was hydrophilic (contact angle is $(70 \pm 1)^{\circ}$ (Fig. 5A). We have revealed that measuring CA of the structured samples is impossible. A drop instantly spreads over and penetrates the surface. Fig. 5B demonstrates the area change of spreading a drop over time as a percentage, where $35 \times 35 \mathrm{~mm}$ square area is $100 \%$. Moreover, the direction and maximum spreading area are different for all the samples. The top view screenshots demonstrate the trace of the drop at the moment when it stops spreading (Fig. 5B): CG - $10 \mathrm{~s} ; \mathrm{G}-17$ $\mathrm{s}$, OG $-24 \mathrm{~s}$. Spreading area of a droplet on Ti reference sample is constant in time. The maximum spreading area is on OG relief. As seen, the fluid extends along the grooves.

Therefore, initiated specific laser parameters have led to changing the surface wettability from hydrophilic to superhydrophilic. It is worth noting that the superhydrophilic surface demonstrates far more highly developed proliferation against superhydrophobic surface. On the one hand, the protein adsorption amount on the hydrophilic surface is significantly more significant than that on the hydrophobic surface [51]. The protein adsorption behavior also plays an important role in cell adhesion. On the other hand, the work [52] casts doubt on the fact that protein adsorption and cell proliferation occur on any hydrophilicity surface, i.e., the factors providing high wettability and the factors providing protein adsorption and cell proliferation are not equivalent. Therefore, additional experiments are required to identify which factor has a strong influence on cell adhesion. However, it should be noted that in our case, one of the factors affecting superhydrophilicity properties is high oxygen content. So, a high oxygen content leads to an increase in protein adsorption, which was also discussed in [52].

EDX-analysis of the surface chemistry showed a significant oxide increase for the laser-treated titanium (Table 3) compared to the nontreated titanium. The oxide percentage for the surface of $O G, G$ and CG reliefs varies within a ratio from 27.42 to $32.73 \mathrm{wt} \%$. Then we accepted that the relief formatting was conducted under similar conditions, so their chemical composition is analogous. We study the effect of nanosecond laser treatment on the phase composition of the nearsurface layers only for OG relief. 
OG
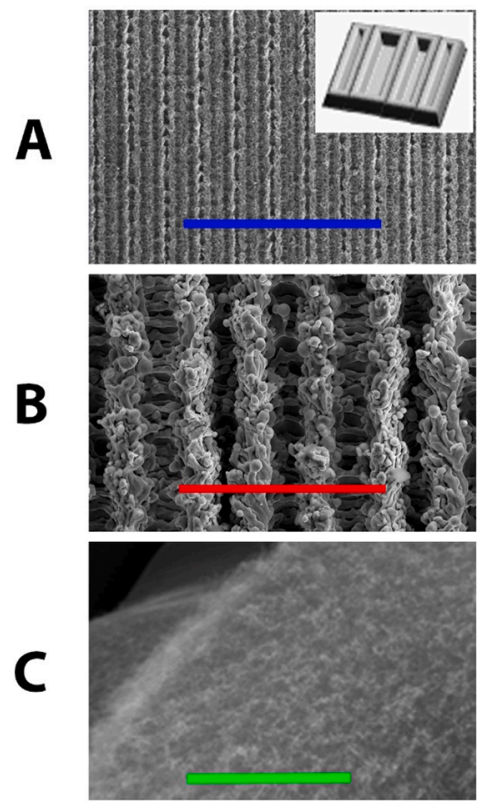

G
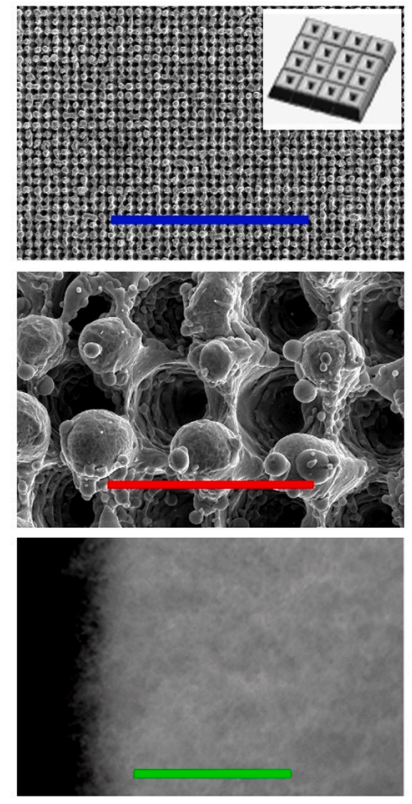

CG
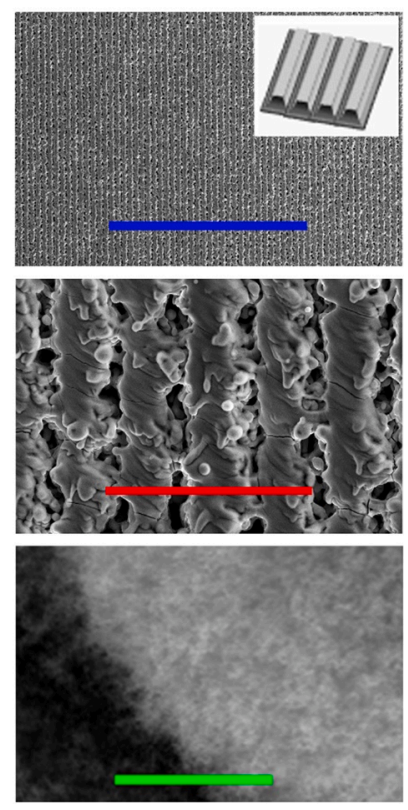

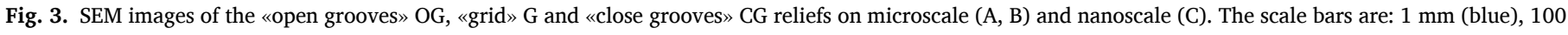
$\mu \mathrm{m}$ (red) and $1 \mu \mathrm{m}$ (green).

Table 2

Roughness of the Ti-surface before (Ti reference) and after (OG, G, CG) laser treatment.

\begin{tabular}{lll}
\hline Sample & Sa, $\mu \mathrm{m}$ & Sdr, $\%$ \\
\hline Ti reference & $0.42 \pm 0.004$ & $6.65 \pm 0.09$ \\
Open grooves OG & $3.85 \pm 0.060$ & $46.57 \pm 5.20$ \\
Grid G & $11.81 \pm 0.150$ & $272.00 \pm 22.30$ \\
Close grooves CG & $3.26 \pm 0.010$ & $43.08 \pm 2.30$ \\
\hline
\end{tabular}

Using the focused ion beam method in the SEM column, the thin cross-section foil was cut (sample with OG relief) to determine its chemical composition. As a result of ion thinning, a sample with a surface area of $7.5 \times 7.5 \mu \mathrm{m}^{2}$, with a thickness of approximately $100 \mathrm{~nm}$, was obtained for subsequent investigation by TEM (Fig. 6A).

Study of the cross-section foil demonstrated that its structure is a branched system of sub-micrometer, micrometer and nanostructures (Fig. 6B). Four zones can be indicated that differ in morphology and phase contrast. Identifying microdiffraction and Fourier transform obtained from images with atomic resolution showed that layers vary in phase composition: $\mathrm{TiO}, \mathrm{Ti}_{2} \mathrm{O}_{3}$ and $\mathrm{TiO}_{2}$ (in the phase of anatase) from depth to surface (Fig. 6, top row). According to the electron-microscopic analysis, the surface layer consists mostly of the agglomerates of $\mathrm{TiO}_{2}$ (in the phase of rutile nanoscale particles with size about $5 \mathrm{~nm}$ ). The formation of a columnar morphology and the oxide layer's porosity is due to the deposition of the oxidized products on the substrate (modified titanium alloy surface), related to laser ablation. The values of experimental interplanar distances compared to the reference data are shown in Table 4.

A thin layer of about $70 \mathrm{~nm}$ can be seen between $\mathrm{TiO}$ and $\mathrm{Ti}_{2} \mathrm{O}_{3}$ layers (at high magnifications). This layer consists of two layers (Fig. 6C). According to EDX analysis in TEM, the nearest to the surface layer is rich with oxygen, and the layer under it contains nitrogen. EDX data in local areas with a diameter of about $2 \mathrm{~nm}$ (local analysis in TEM) as well as the data of element analysis along the line (depth profile) correlate with electron-microscopic analysis data. With an increase in depth, the concentration of oxygen decreases. The data given suggests the phase transition with a formation of layered oxide structures of various phase composition occurring on the modified surface, which correlates with theoretical calculations [55]. $\mathrm{Ti}_{2} \mathrm{O}_{3}$ crystallites are rich with nitrogen, and $\mathrm{Ti}_{2} \mathrm{O}_{3} \mathrm{~N}_{\mathrm{x}}$ phase with distorted hexagonal lattice is present because nitrogen (interstitial impurity) fits into lattice interstices. Calculations showed that parameter "a" of the lattice increases, whereas parameter "c" decreases (Table 4).

The titanium oxynitride coatings have high values of nanohardness and Young's modulus $[55,56]$, but have no direct effect on cell behavior. Nevertheless, our nanostructures consist of these oxides. As was shown in $[57,58]$, a nanorelief enhanced interaction with cells and biological fluids at the early stages of biointegration.

\subsection{Analysis of cell proliferation, depthward colonization and osteogenic differentiation}

For in vitro investigation we used hMSCs, that are a good model environment for studies at the early stages of osseointegration. A series of in vitro tests were conducted on the reliefs obtained compared to the original polished titanium alloy (Ti). The dynamic colonisation and hMSCs-Turbo FP635 cells proliferation was comparatively studied over 20 days using fluorescent imaging (Fig. 7). Quantitative analysis of cell proliferation on the implant's surface via fluorescent bioimaging of hMSCs-Turbo FP635 is presented in Fig. 8.

After $24 \mathrm{~h}$, the seeded cells were found on all types of samples. On Ti the cells were arranged in an even layer and had a fibroblast-like elongated shape indicating their normal adhesion. Day after day the number of viable cells decreased from the initial quantity and reached zero point on day 20. After the first $24 \mathrm{~h} \mathrm{G}$ and CG reliefs had single round-shaped hMSCs-TurboFP635, characteristic of incomplete adhesion to the surface. On day 20 the number of viable cells reached 165650 cells/sample for CG and 196000 cells/sample for G, respectively. On OG relief the cells were arranged in an even layer and had a fibroblast-like elongated shape indicating their normal adhesion on the first day after seeding. Fig. 6 demonstrates the most considerable proliferation for each day of investigation. The final value reached 266500 cells/sample - the maximal number among all samples. 

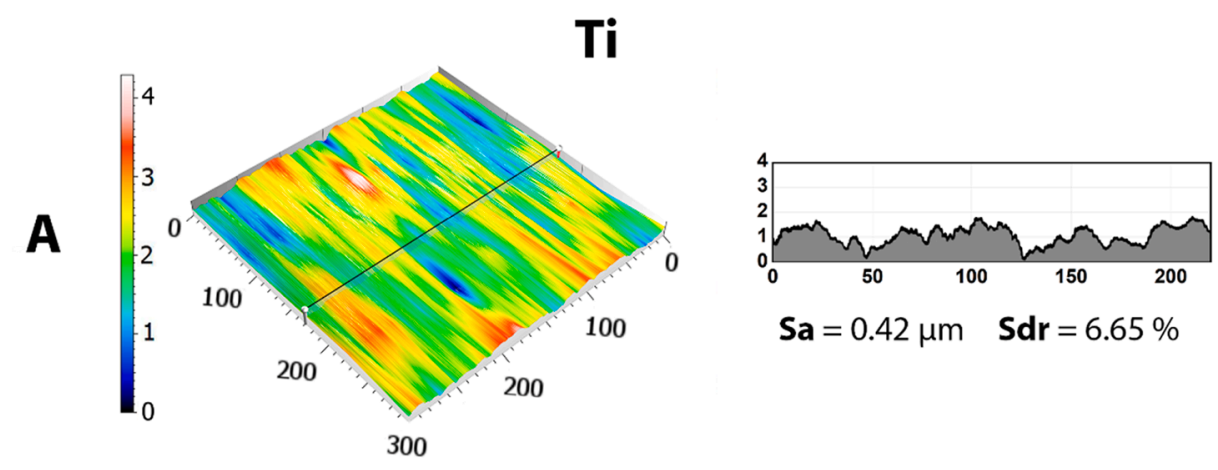

$$
\mathbf{S a}=0.42 \mu \mathrm{m} \quad \mathbf{S d r}=6.65 \%
$$
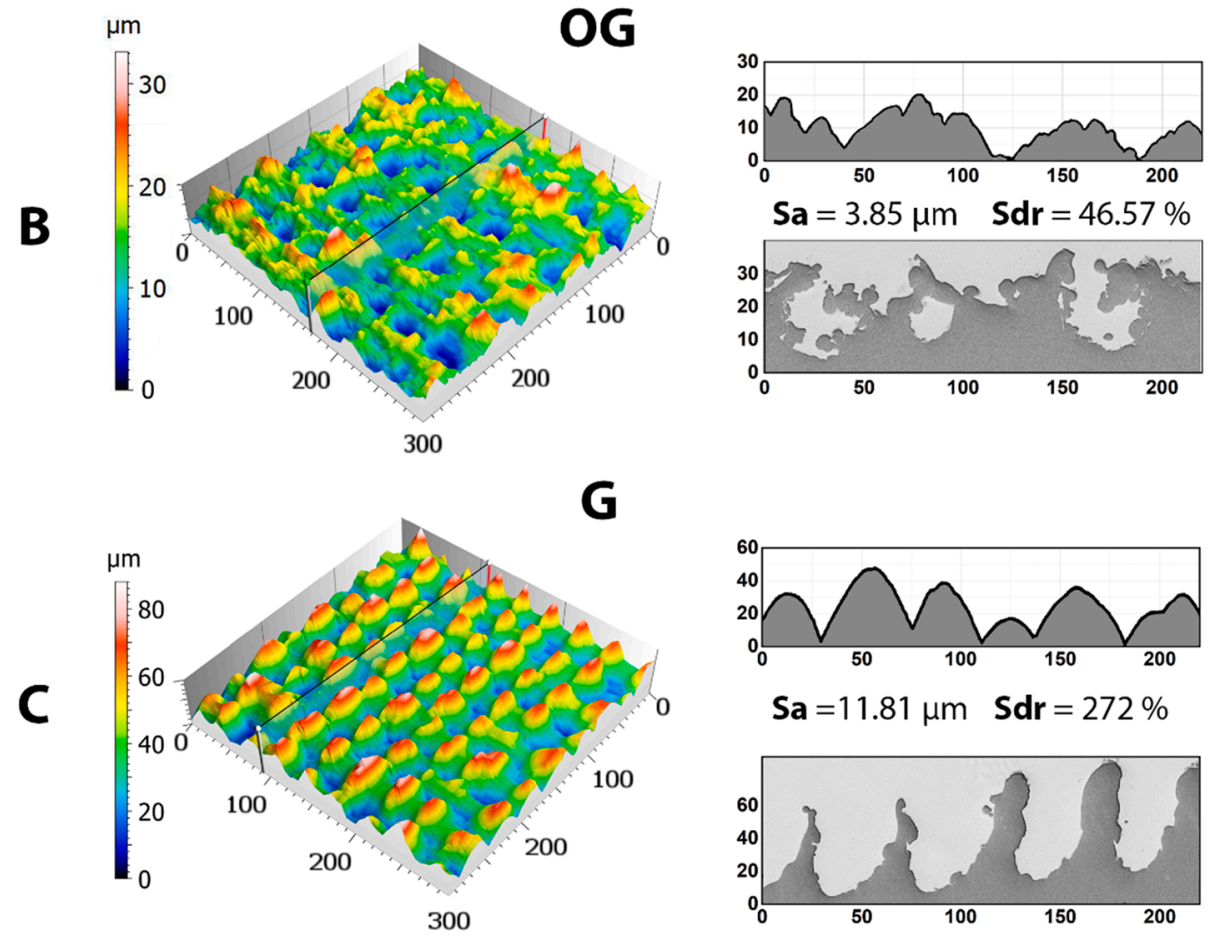

$\mathbf{S a}=11.81 \mu \mathrm{m} \quad \mathbf{S d r}=272 \%$
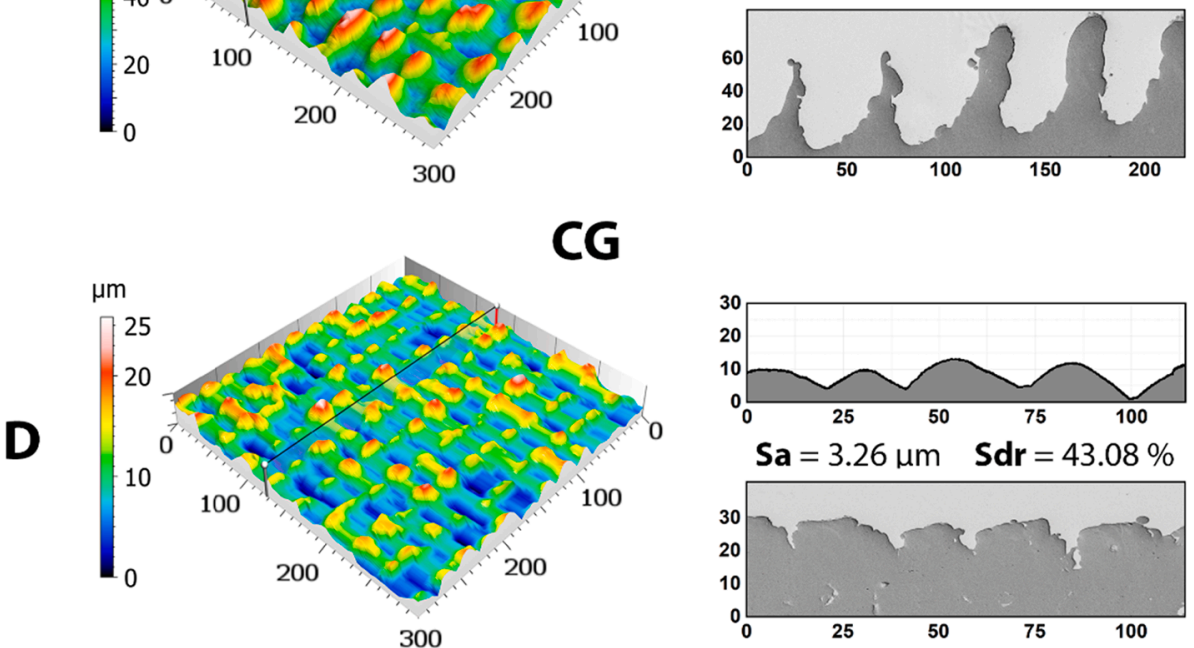

Fig. 4. 3D surfaces of the reliefs; calculated three-dimensional parameters Sa and Sdr; profiles and cross-sections of the «open grooves» OG (A), «grid» G (B) and «close grooves» CG (C).

The analysis of cell alignment indicates that OG and CG reliefs have an impact on directed cells growth. Interestingly, the cells elongated in the grooves were found on the first day for OG relief and day 10 for the CG relief.

It should be noted that the quantitative analysis does not take into account the cells that germinate inwards into the open pores. Qualitative analysis of cell growth into the implant from the surface on day 20 is demonstrated in Fig. 9. The results obtained show that the cells are located not only on the tops of the topographies but also cover their bottom and grow inward in open pores.
Osteogenesis was investigated through an expression of osteocalcin and an ALP activity test. Qualitative analysis of osteocalcin expression via immunocytochemical staining of the hMSCs with the antiosteocalcin antibodies on day 20 is shown in Fig. 10. Osteocalcin is the most informative marker of bone formation. Osteocalcin is released by osteoblasts during osteogenesis. Green fluorescence indicates osteocalcin (Opal-520 staining), blue fluorescence - cell nuclei (Hoechst 33,342 staining). All reliefs develop some quantity of osteocalcin. The minimum of osteocalcin corresponds to CG relief. G and OG reliefs have approximately the same quantity of osteocalcin. 
A
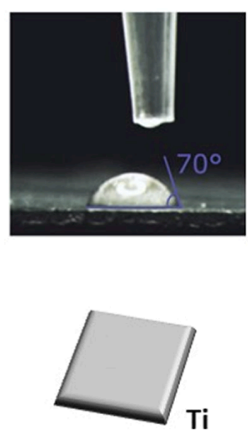

B

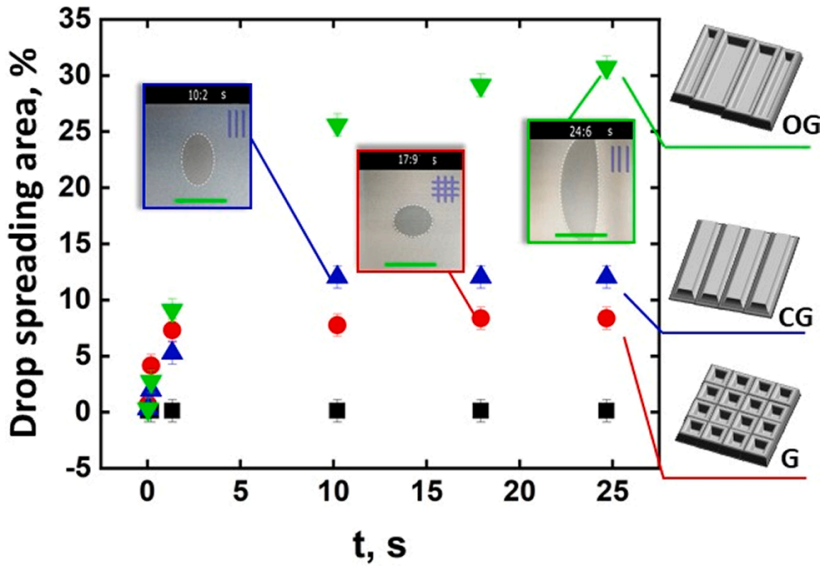

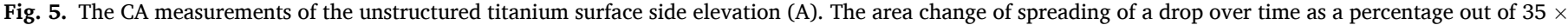

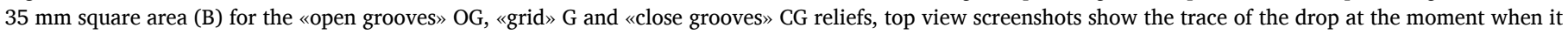
stopped spreading. The scale bar is $2 \mathrm{~cm}$ (green).

Table 3

Elemental composition of the Ti-surface before (Ti reference) and after (OG, G, CG) laser treatment (EDX-analysis).

\begin{tabular}{llllr}
\hline Element, wt \% & $\mathrm{Ti}$ & $\mathrm{Al}$ & $\mathrm{V}$ & \multicolumn{1}{l}{$\mathrm{O}$} \\
\hline Ti reference & 89.41 & 5.56 & 4.82 & 0.21 \\
OG & 66.04 & 3.07 & 3.47 & 27.42 \\
G & 61.10 & 2.66 & 3.51 & 32.73 \\
CG & 62.02 & 4.52 & 3.44 & 30.02 \\
\hline
\end{tabular}

The fluorescence imaging shows the differences between shapes and sizes of the cell nucleus for each sample. The nuclei of the cells cultured on $G$ and $C G$ reliefs have a rounded shape and the same size. For OG relief the cell nucleus is oval-shaped and possesses the smallest size compared to the other reliefs.

The second osteogenesis marker was the ALP activity (Fig. 11). The background level - a medium with no secreted ALP, served as a negative control. ALP was determined in all reliefs. The results correlate with the expression of osteocalcin results. Maximum ALP activity is observed for OG relief, a minimum - for CG relief. ALP activity of the G relief is similar to that one of the CG relief in view error.

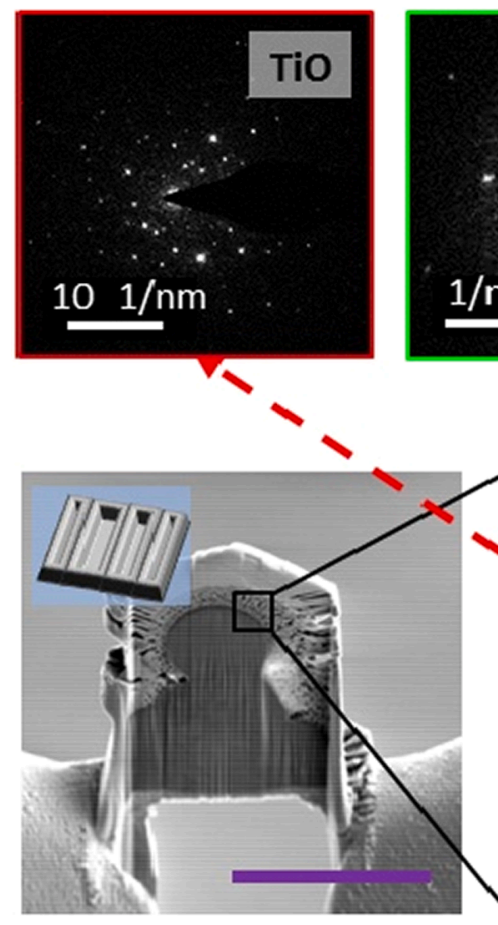

A

$A$
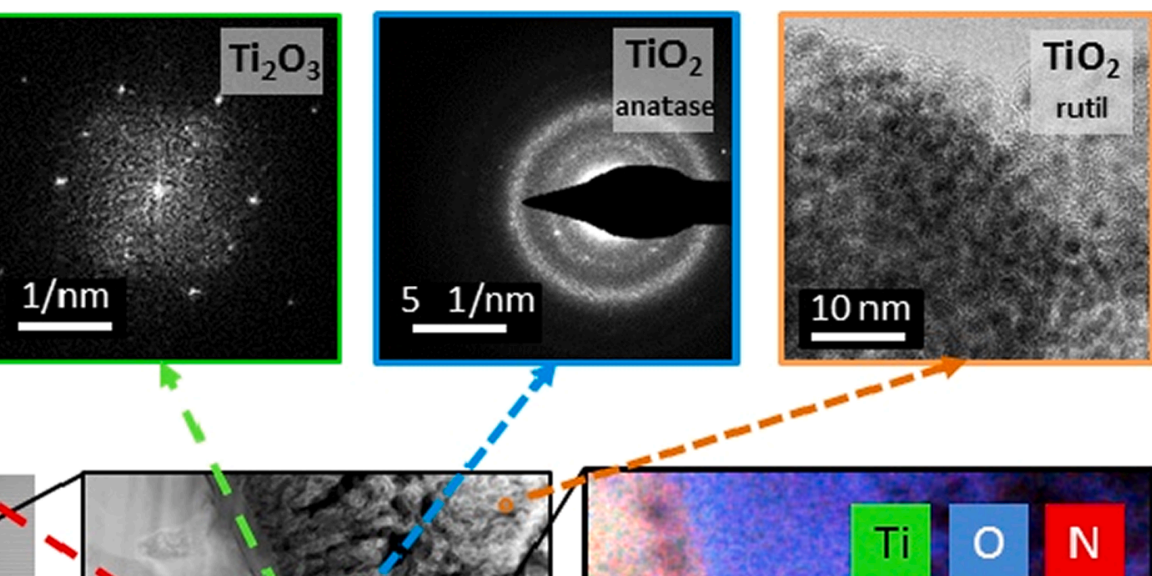

B

C

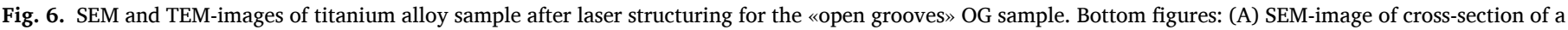

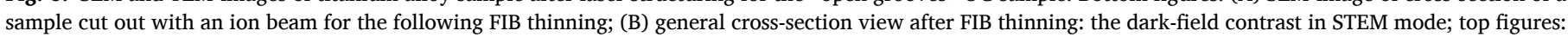

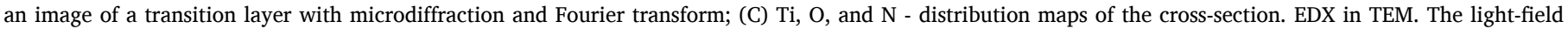
contrast in STEM. Color dots identify the qualifying distribution of the Ti-oxide phases. The scale bars are $20 \mu \mathrm{m}$ (violet), $100 \mathrm{~nm}$ (blue). 
Table 4

Values of interplanar distances of titanium oxide phases (experimental and reference).

\begin{tabular}{|c|c|c|c|c|c|c|c|c|}
\hline \multicolumn{2}{|l|}{$\mathrm{TiO}_{2}$ (rutile) } & \multicolumn{2}{|l|}{$\mathrm{TiO}_{2}$ (anatase) } & \multicolumn{2}{|l|}{$\mathrm{TiO}$} & \multicolumn{2}{|l|}{$\mathrm{Ti}_{2} \mathrm{O}_{3}$} & \multirow{2}{*}{$\begin{array}{l}\frac{\mathrm{Ti}_{2} \mathrm{O}_{3} \text { with } \mathrm{N}}{\text { exp. meas., hexagonal }} \\
\text { lattice [56], } \mathrm{a}=5.2 \AA \text {; } \mathrm{c}= \\
13.235 \AA\end{array}$} \\
\hline $\begin{array}{l}\text { tetragonal lattice }[53], \mathrm{a}= \\
2.959 \AA \AA \mathrm{̊}=4.593 \AA \mathrm{c}= \\
4.593 \AA\end{array}$ & $\begin{array}{l}\text { exp. } \\
\text { meas. }\end{array}$ & 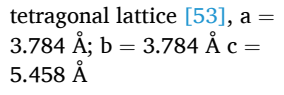 & $\begin{array}{l}\text { exp. } \\
\text { meas. }\end{array}$ & $\begin{array}{l}\text { cubic lattice } \\
{[54], \mathrm{a}=} \\
2.95 \AA\end{array}$ & $\begin{array}{l}\text { exp. } \\
\text { meas. }\end{array}$ & $\begin{array}{l}\text { hexagonal lattice [55], } \\
\mathrm{a}=5.146 \AA \text { A } \mathrm{c}= \\
13.547 \AA\end{array}$ & $\begin{array}{l}\text { exp. } \\
\text { meas. }\end{array}$ & \\
\hline $3.248(110)$ & 3.21 & $3.516(101)$ & 3.60 & $2.412(111)$ & 2.50 & $3.723(012)$ & 3.74 & 3.52 \\
\hline $2.488(101)$ & 2.48 & $2.431(103)$ & 2.44 & $2.089(200)$ & 2.20 & $2.696(104)$ & 2.70 & 2.67 \\
\hline $2.297(200)$ & 2.30 & $2.379(004)$ & 2.38 & $1.477(220)$ & 1.40 & $2.573(110)$ & 2.6 & 2.55 \\
\hline $2.187(111)$ & 2.20 & $1.758(202)$ & 1.76 & $1.259(311)$ & 1.26 & $2.235(11-3)$ & 2.22 & - \\
\hline
\end{tabular}
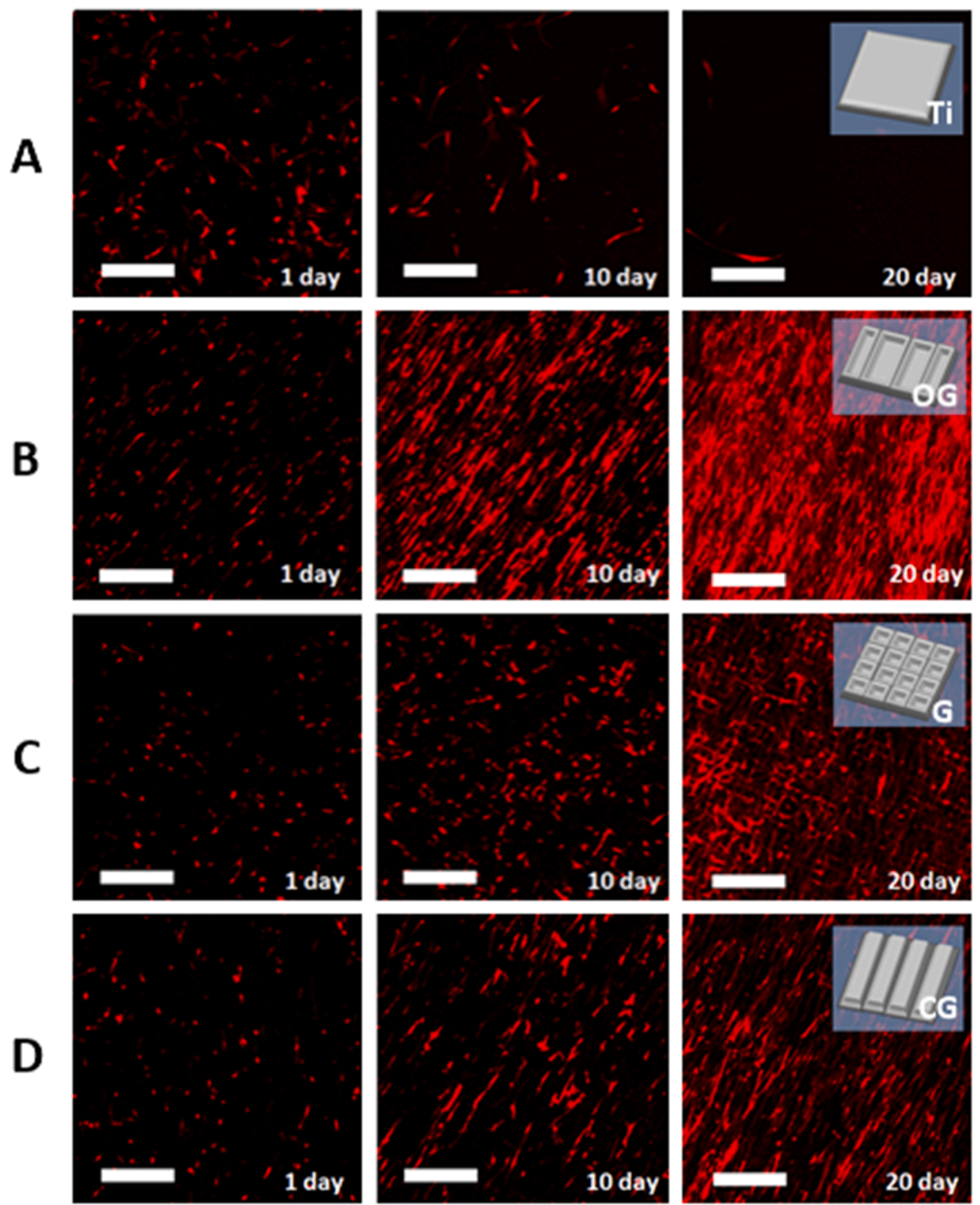

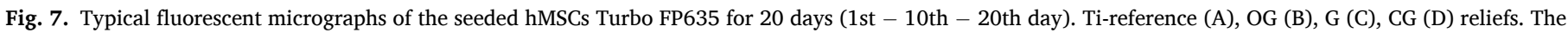

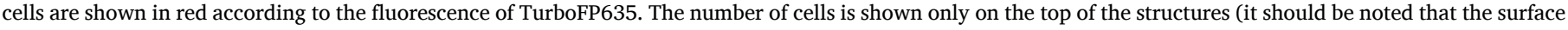
area is different for 4 samples). The scale bars are $300 \mu \mathrm{m}$ for all images.

In general, osteogenic differentiation requires sufficient attachment of multipotent MSCs to the substrate (implant) and their subsequent spreading $[59,60]$. Cells attach to the substrate by a focal contact (focal adhesions) $[61,62]$. The main molecules of focal contacts are integrins, which consist of the $\alpha$ - and $\beta$-subunits [63]. They ensure the attachment of cells to the substrate. Integrins are sensitive to the biochemical and biophysical characteristics of cellular substrates. Thus, osteogenic cells, using integrin receptors [63], assess the quality of the substrate: the rigidity of the substrates, their chemical composition, and surface topography. 


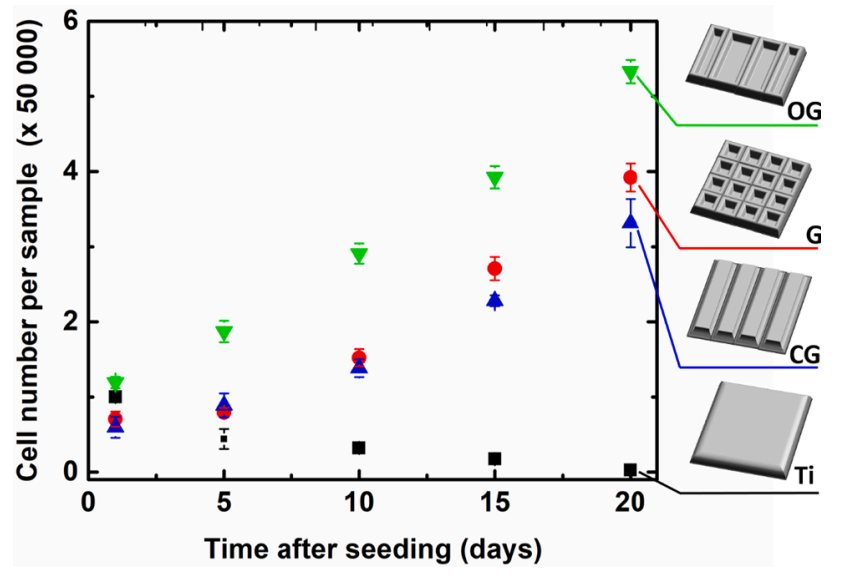

Fig. 8. Quantitative (1st -5 th -10 th -15 th -20 th days) analysis of cell proliferation for 20 days for the OG, G, CG and Ti reference surface.

In our case, if the chemical composition played a decisive role in osteogenic differentiation of MSCs, the percentage increase of oxygen on the sample surface would occur in accord with increase of ALP activity in the following order: CG, G, OG. However, this is not so: the maximum amount of oxygen corresponds to the OG relief, the minimum - to the $\mathrm{G}$ relief. The same can be said about the rigidity of the surface because it directly depends on the chemical composition and crystal structure of the surface, although such an assessment has not been carried out. Thus, the difference in osteogenic differentiation for various surface reliefs is associated precisely with its geometric structure. From this point of view, grooves with a width and depth commensurate with the cells size make it possible for cells to spread in both directions. It is possible, a larger number of focal contacts for the OG sample is formed due to the presence of the most developed relief on the groove walls in comparison with the G and CG reliefs. Thus, the microrelief plays a decisive role in the firm adhesion of cells to the surface. It should be added that for deep analysis of reasons why various surface reliefs induced different osteogenic differentiation, it is necessary to study the mechanisms of attachment and spreading of single MSCs on reliefs, which is our future research topic. Nevertheless, observed cells behavior is related to the chemical composition change together with the relief change.

\section{Conclusions}

In the present work, we have used the nanosecond laser structuring for changing the chemical composition and surface relief for Ti-6A1-4V titanium disks of $1 \mathrm{~mm}$ thickness and $5 \mathrm{~mm}$ diameter. We have developed the laser processing conditions that provide the formation of wellordered rough surface with subcellular to cellular period of structures. The following reliefs have been formed: «open grooves» with the period of $30.20( \pm 2.40) \mu \mathrm{m}, \mathrm{Sa}=3.85( \pm 0.06) \mu \mathrm{m}$ and $\mathrm{Sdr}=46.57( \pm 5.20) \%$;

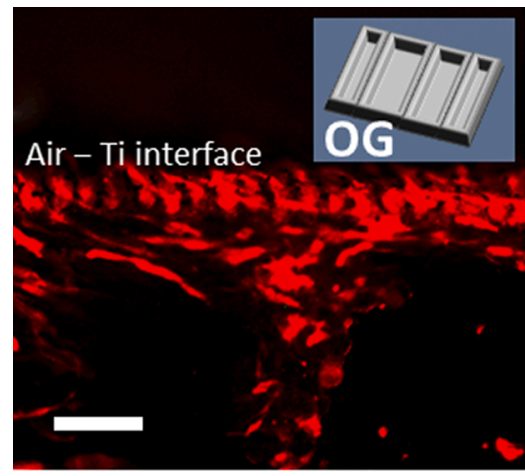

A

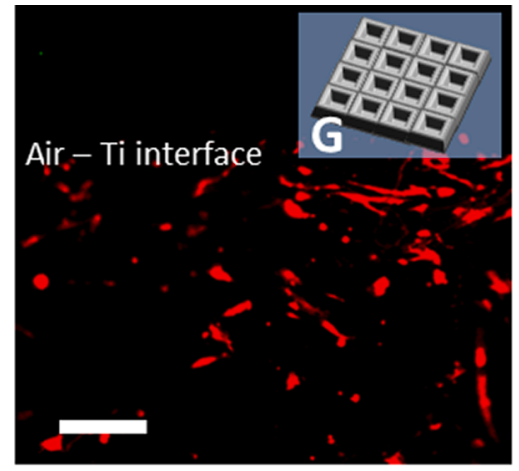

B

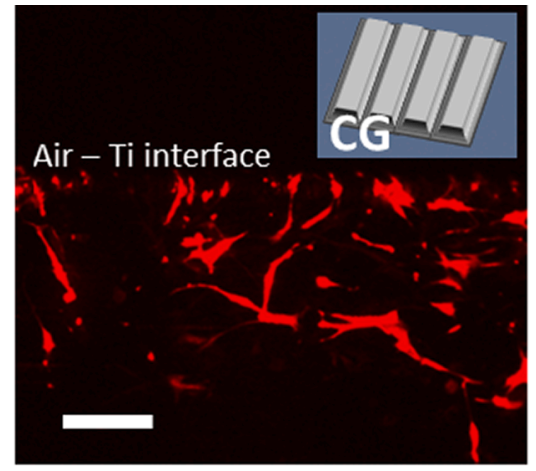

C

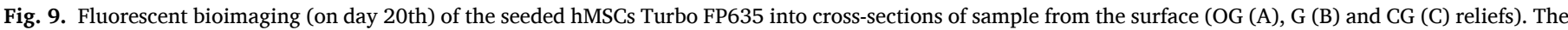

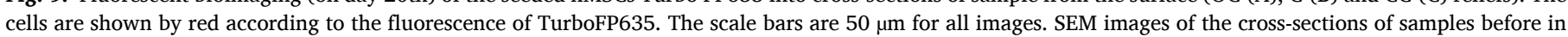
vitro research are in Fig. 4.

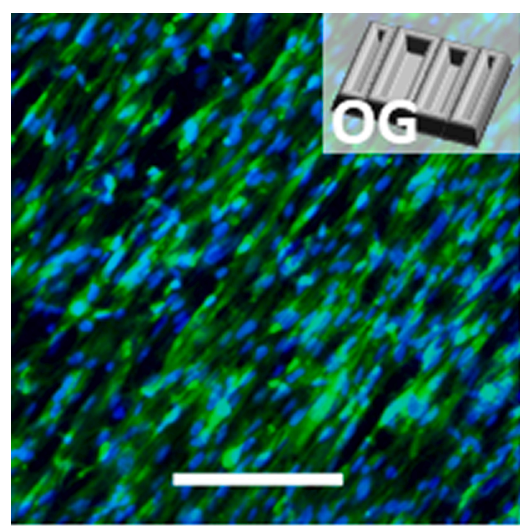

A

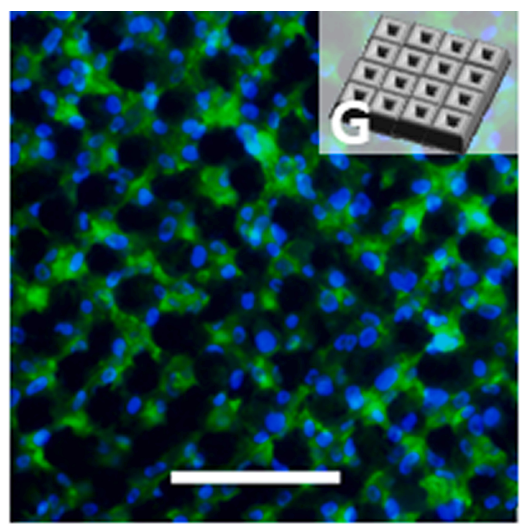

B

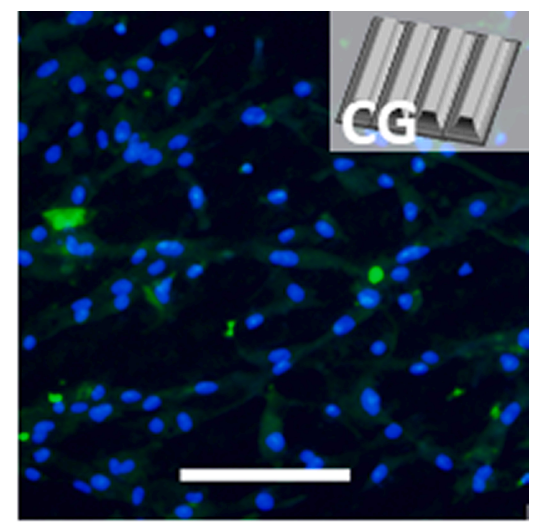

C

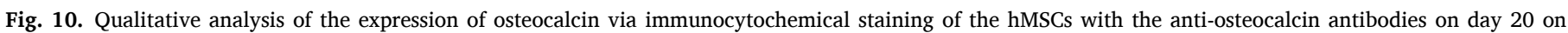

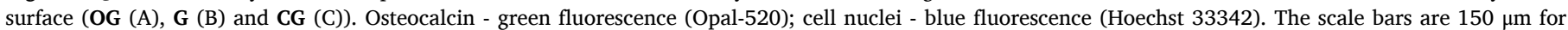
all images. 


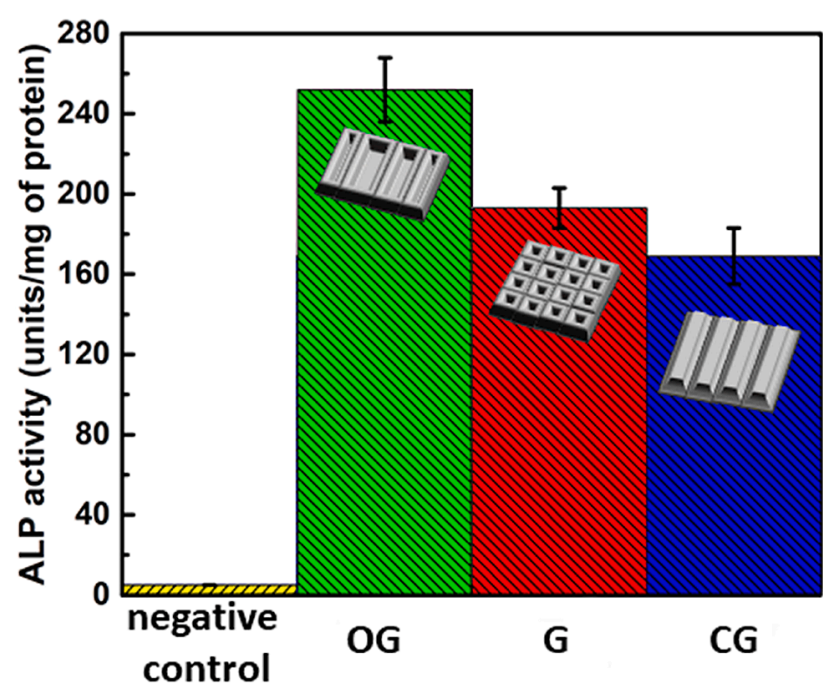

Fig. 11. Quantitative analysis of ALP activity via fluorometric assay of culture medium on day 20 for OG (B), G (C) and CG (D) reliefs.

«grid» with the period of $49.50( \pm 4.60) \mu \mathrm{m}, \mathrm{Sa}=11.81( \pm 0.15) \mu \mathrm{m}$ and $\mathrm{Sdr}=272.00( \pm 22.30) \%$; and «close grooves», with the period of 31.40 $( \pm 3.30) \mu \mathrm{m}, \mathrm{Sa}=3.26( \pm 0.01) \mu \mathrm{m}$ and $\mathrm{Sdr}=43.08( \pm 2.30) \%$. The porous oxide layer coats the surface of the reliefs. The surface composition has a sandwich structure: $\mathrm{Ti} \rightarrow \mathrm{TiO} \rightarrow \mathrm{Ti}_{2} \mathrm{O}_{3} \mathrm{Nx} \rightarrow \mathrm{TiO}_{2}$ (anatase) $\rightarrow \mathrm{TiO}_{2}$ (rutile).

As a result of the wettability studies, it was found that all reliefs are superhydrophilic, and the area, direction and time of spreading of a liquid droplet are different for the three presented reliefs. Maximum spreading area was achieved on the «open grooves». The fluid distributed predominantly along the grooves.

Current results clearly demonstrated that OG relief is the best for cells differentiation, alignment and osteocalcin genesis among investigated reliefs.

The proliferation study showed that, compared with the untreated titanium surface, the cells proliferated perfectly in all reliefs. However, the maximum number of cells on day 20 was found on the surface of the «open grooves» 266,500 cells/sample. The results obtained showed the cells cover both tops and bottoms of the topographies, as well as grow inward in open pores.

The in vitro study revealed that the relief affects the spatial orientation of cells: hMSCs extend along the «open grooves», while the «close grooves», which have the same roughness, does not influence the spatial orientation of cells. It was noted that the shape and size of the cell nuclei for the different topographies diverge. On the «open grooves» surface, the nuclei have the smallest size and elongated ellipsoidal shape. On the surface of the «close grooves», the cell nucleus structure was rounded and larger in size compared to the «open grooves». The cell nuclei on the grid structure are round in shape of medium size.

The osteocalcin expression study showed that osteogenesis occurred on all reliefs. The most significant amount of osteocalcin was found on «open grooves». The data are confirmed by the results of the ALP activity test.

This study demonstrates that a surface relief and Sa roughness, which significantly exceeds $2 \mu \mathrm{m}$, positively affects osteogenesis, as is the case with NSCs [45]. We have found that it is beneficial for cells to have not individual slots but structures like a groove, with the distance between the peaks with subcellular to cellular scales. The results of this comprehensive study show that the cells-implants interaction between cells and implant surfaces is affected not only by surface microroughness, as most implant manufacturers claims, but also by the relief, which includes continuous topography with the features less than $50 \mu \mathrm{m}$ and the presence of nanostructures. Therefore, we suggest that it should be taken into account the geometric structure of the surface to manufacture dental implants.

This study is preliminary and examines only cells layer as a whole. It is planned to conduct a more detailed study on the behavior of single MSCs on these structures with a description of these mechanisms and the influence of surface micro-geometry on the vital activity of cells.

\section{Funding}

The study was supported by the Russian Science Foundation (project № 20-62-46045).

\section{CRediT authorship contribution statement}

Vadim Veiko: Conceptualization, Methodology. Yulia Karlagina: Validation, Formal analysis, Investigation, Writing - original draft, Writing - review \& editing, Visualization. Tatiana Itina: Writing original draft, Writing - review \& editing. Daria Kuznetsova: Investigation. Vadim Elagin: Investigation. Elena Zagaynova: Investigation. Gennady Chernenko: Resources. Elena Egorova: Formal analysis, Software, Writing - review \& editing, Visualization. Catherine Zernitskaia: Conceptualization. Sergey Manokhin: Investigation, Writing original draft. Anastasia Tokmacheva-Kolobova: Investigation. Galina Odintsova: Methodology, Writing - original draft, Writing - review \& editing, Supervision, Project administration.

\section{Declaration of Competing Interest}

The authors declare that they have no known competing financial interests or personal relationships that could have appeared to influence the work reported in this paper.

\section{Acknowledgments}

The creating of thin foils using ion beams took place at the Federal Research Center "Crystallography and photonics" of Russian Academy of Science.

T. E. I. gratefully acknowledges the ITMO Invited Professorship.

G.V.O. gratefully acknowledges Eduard Ageev for fruitful discussion.

\section{Declaration of Competing Interest}

The authors declare that they have no known competing financial interests or personal relationships that could have appeared to influence the work reported in this paper.

\section{References}

[1] T. Albrektsson, A. Wennerberg, On osseointegration in relation to implant surfaces, Clin. Implant Dent. Relat. Res. 21 (2019) 4-7, https://doi.org/10.1111/cid.12742.

[2] A.D. Pye, D.E.A. Lockhart, M.P. Dawson, C.A. Murray, A.J. Smith, A review of dental implants and infection, J. Hosp. Infect. 72 (2009) 104-110, https://doi.org/ 10.1016/j.jhin.2009.02.010.

[3] K. Almas, S. Smith, A. Kutkut, What is the best micro and macro dental implant topography? Dent. Clin. North Am. 63 (2019) 447-460, https://doi.org/10.1016/j. cden.2019.02.010.

[4] F. Javed, G.E. Romanos, The role of primary stability for successful immediate loading of dental implants. A literature review, J. Dent. 38 (2010) 612-620, https://doi.org/10.1016/j.jdent.2010.05.013.

[5] F. Rupp, L. Liang, J. Geis-Gerstorfer, L. Scheideler, F. Hüttig, Surface characteristics of dental implants: a review, Dent. Mater. 34 (2018) 40-57, https://doi.org/ 10.1016/j.dental.2017.09.007.

[6] K.-H. Kramer, Implants for surgery - a survey on metallic materials, Mater. Med. Eng. (2005) 9-29, https://doi.org/10.1002/3527606149.ch2.

[7] M. Textor, C. Sittig, V. Frauchiger, S. Tosatti, D.M. Brunette, Properties and Biological Significance of Natural Oxide Films on Titanium and Its Alloys, 2001, pp. 171-230. https://doi.org/10.1007/978-3-642-56486-4_7.

[8] D. Buser, N. Broggini, M. Wieland, R.K. Schenk, A.J. Denzer, D.L. Cochran, B. Hoffmann, A. Lussi, S.G. Steinemann, Enhanced bone apposition to a chemically modified SLA titanium surface, J. Dent. Res. 83 (2004) 529-533, https://doi.org/ $10.1177 / 154405910408300704$. 
[9] G. Zhao, Z. Schwartz, M. Wieland, F. Rupp, J. Geis-Gerstorfer, D.L. Cochran, B. D. Boyan, High surface energy enhances cell response to titanium substrate microstructure, J. Biomed. Mater. Res. - Part A. 74 (2005) 49-58, https://doi.org/ 10.1002/jbm.a.30320.

[10] E. Velasco-Ortega, I. Ortiz-García, A. Jiménez-Guerra, L. Monsalve-Guil, F. MuñozGuzón, R.A. Perez, F.J. Gil, Comparison between sandblasted acid-etched and oxidized titanium dental implants: in vivo study, Int. J. Mol. Sci. 20 (2019), https://doi.org/10.3390/ijms20133267.

[11] M. Gahlert, S. Röhling, M. Wieland, C.M. Sprecher, H. Kniha, S. Milz, Osseointegration of zirconia and titanium dental implants: a histological and histomorphometrical study in the maxilla of pigs, Clin. Oral Implants Res. 20 (2009) 1247-1253, https://doi.org/10.1111/j.1600-0501.2009.01734.x.

[12] L. Le Guéhennec, A. Soueidan, P. Layrolle, Y. Amouriq, Surface treatments of titanium dental implants for rapid osseointegration, Dent. Mater. 23 (2007) 844-854, https://doi.org/10.1016/j.dental.2006.06.025.

[13] E.A. Bonfante, C. Marin, R. Granato, M. Suzuki, J. Hjerppe, L. Witek, P.G. Coelho, Histologic and biomechanical evaluation of alumina-blasted/acid-etched and resorbable blasting media surfaces, J. Oral Implantol. 38 (2012) 549-556, https:// doi.org/10.1563/AAID-JOI-D-10-00105.

[14] J.W. Choi, S.J. Heo, J.Y. Koak, S.K. Kim, Y.J. Lim, S.H. Kim, J.B. Lee, Biological responses of anodized titanium implants under different current voltages, J. Oral Rehabil. 33 (2006) 889-897, https://doi.org/10.1111/j.1365-2842.2006.01669.x.

[15] A.-A. Aalam, H. Nowzari, Clinical evaluation of dental implants with surfaces roughened by anodic oxidation, dual acid-etched implants, and machined implants, Int. J. Oral Maxillofac. Implants. 20 (2005) 793-798.

[16] B.R. Chrcanovic, T. Albrektsson, A. Wennerberg, Turned versus anodised dental implants: a meta-analysis, J. Oral Rehabil. 43 (2016) 716-728, https://doi.org/ 10.1111/joor.12415.

[17] Y.-T. Sul, C.B. Johansson, S. Petronis, A. Krozer, Y. Jeong, A. Wennerberg, T. Albrektsson, Characteristics of the surface oxides on turned and electrochemically oxidized pure titanium implants up to dielectric breakdown, Biomaterials 23 (2002) 491-501, https://doi.org/10.1016/s0142-9612(01)00131 4.

[18] T.S. Petrovskaya, V.I. Vereschagin, Effectiveness of the technologies of titanium implants covering, Key Eng. Mater. 670 (2015) 183-188, https://doi.org/10.4028/ www.scientific.net/KEM.670.183.

[19] D. Berardi, S. de Benedittis, A. Scoccia, G. Perfetti, P. Conti, New laser-treated implant surfaces: a histologic and histomorphometric pilot study in rabbits, Clin. Investig. Med. (2011) E202-E210.

[20] S.-A. Cho, S.-K. Jung, A removal torque of the laser-treated titanium implants in rabbit tibia, Biomaterials 24 (2003) 4859-4863.

[21] C. Hallgren, H. Reimers, D. Chakarov, J. Gold, A. Wennerberg, An in vivo study of bone response to implants topographically modified by laser micromachining, Biomaterials 24 (2003) 701-710.

[22] R. Honda, M. Mizutani, H. Ohmori, J. Komotori, Biocompatibility evaluation of nanosecond laser treated titanium surfaces, Int. J. Mod. Phys. Conf. Ser. 06 (2012) 682-687, https://doi.org/10.1142/s2010194512003972.

[23] F.A. Shah, M.L. Johansson, O. Omar, H. Simonsson, A. Palmquist, P. Thomsen, Laser-modified surface enhances osseointegration and biomechanical anchorage of commercially pure titanium implants for bone-anchored hearing systems, PLoS One 11 (2016) 1-24, https://doi.org/10.1371/journal.pone.0157504.

[24] O. Raimbault, S. Benayoun, K. Anselme, C. Mauclair, T. Bourgade, A.M. Kietzig, P. L. Girard-Lauriault, S. Valette, C. Donnet, The effects of femtosecond laser-textured Ti-6Al-4V on wettability and cell response, Mater. Sci. Eng. C. 69 (2016) 311-320, https://doi.org/10.1016/j.msec.2016.06.072.

[25] A.Y. Fasasi, S. Mwenifumbo, N. Rahbar, J. Chen, M. Li, A.C. Beye, C.B. Arnold, W. O. Soboyejo, Nano-second UV laser processed micro-grooves on Ti6Al4V for biomedical applications, Mater. Sci. Eng. C. 29 (2009) 5-13, https://doi.org/ 10.1016/j.msec.2008.05.002.

[26] S. Çelen, H. Özden, Laser-induced novel patterns: as smart strain actuators for newage dental implant surfaces, Appl. Surf. Sci. 263 (2012) 579-585, https://doi.org/ 10.1016/j.apsusc.2012.09.112.

[27] P. Schupbach, R. Glauser, S. Bauer, Al2O3 particles on titanium dental implant systems following sandblasting and acid-etching process, Int. J. Biomater. 2019 (2019) 9-12.

[28] V. Milleret, P.S. Lienemann, A. Gasser, S. Bauer, M. Ehrbar, A.W. Dds, Rational design and in vitro characterization of novel dental implant and abutment surfaces for balancing clinical and biological needs, Clin. Impl. Dent. Relat. Res. (2019) 1-10, https://doi.org/10.1111/cid.12736.

[29] Y. Sul, C.B. Johansson, S. Petronis, A. Krozer, A. Wennerberg, T. Albrektsson, Characteristics of the surface oxides on turned and electrochemically oxidized pure titanium implants up to dielectric breakdown : the oxide thickness, micropore configurations, surface roughness, crystal structure and chemical composition, Biomaterials 23 (2002) 491-501.

[30] A.Y. Vorobyev, C. Guo, Femtosecond laser surface structuring of biocompatible metals, Commer. Biomed. Appl. Ultrafast Lasers IX. 7203 (2009) 720300, https:// doi.org/10.1117/12.809593.

[31] Z. Yu, G. Yang, W. Zhang, J. Hu, Investigating the effect of picosecond laser texturing on microstructure and biofunctionalization of titanium alloy, J. Mater. Process. Technol. 255 (2018) 129-136, https://doi.org/10.1016/j. jmatprotec.2017.12.009.

[32] N. Mirhosseini, P.L. Crouse, M.J.J. Schmidth, L. Li, D. Garrod, Laser surface microtexturing of Ti-6Al-4V substrates for improved cell integration, Appl. Surf. Sci. 253 (2007) 7738-7743, https://doi.org/10.1016/j.apsusc.2007.02.168.

[33] V. Dumas, A. Rattner, L. Vico, E. Audouard, J.C. Dumas, P. Naisson, P. Bertrand, Multiscale grooved titanium processed with femtosecond laser influences mesenchymal stem cell morphology, adhesion, and matrix organization, J. Biomed. Mater. Res. - Part A. 100 A (2012) 3108-3116, https://doi.org/10.1002/jbm. a.34239.

[34] I. De Tullio, M. Berardini, D. Di Iorio, F. Perfetti, G. Perfetti, Comparative evaluation among laser-treated, machined, and sandblasted/acid-etched implant surfaces: an in vivo histologic analysis on sheep, Int. J. Implant Dent. 6 (2020) 4-11, https://doi.org/10.1186/s40729-019-0204-4.

[35] E. Fadeeva, V.K. Truong, M. Stiesch, B.N. Chichkov, R.J. Crawford, J. Wang, E. P. Ivanova, Bacterial retention on superhydrophobic titanium surfaces fabricated by femtosecond laser ablation, Langmuir 27 (2011) 3012-3019, https://doi.org/ 10.1021/la104607g.

[36] A.Y. Vorobyev, C. Guo, Femtosecond laser structuring of titanium implants, Appl. Surf. Sci. 253 (2007) 7272-7280, https://doi.org/10.1016/j.apsusc.2007.03.006.

[37] A. Gaggl, G. Schultes, W.D. Müller, H. Kärcher, Scanning electron microscopical analysis of laser-treated titanium implant surfaces-a comparative study, Biomaterials 21 (2000) 1067-1073, https://doi.org/10.1016/S0142-9612(00) 00002-8.

[38] R. Leach, Characterisation of Areal Surface Texture, Springer Science \& Business Media, 2013. https://doi.org/10.1007/978-3-642-36458-7.

[39] M. Scacchi, B.R. Merz, A.R. Schär, The development of the ITI DENTAL IMPLANT SYSTEM. Part 2: 1998-2000: steps into the next millennium, Clin. Oral Implants Res. 11 (Suppl 1) (2000) 22-32, https://doi.org/10.1034/j.16000501.2000.011S1022.x.

[40] V. Milleret, P.S. Lienemann, S. Bauer, M. Ehrbar, Quantitative in vitro comparison of the thrombogenicity of commercial dental implants, Clin. Impl. Dent. Relat. Res. (2019) 1-7, https://doi.org/10.1111/cid.12737.

[41] H. De Bruyn, V. Christiaens, R. Doornewaard, M. Jacobsson, J. Cosyn, W. Jacquet, S. Vervaeke, Implant surface roughness and patient factors on long-term periimplant bone loss, Periodontol. 2000 (73) (2017) 218-227, https://doi.org/ 10.1111/prd.12177.

[42] A. Wennerberg, T. Albrektsson, Effects of titanium surface topography on bone integration: a systematic review, Clin. Oral Implants Res. 20 (2009) 172-184, https://doi.org/10.1111/j.1600-0501.2009.01775.x.

[43] K.Y. Hung, S.C. Lo, C.S. Shih, Y.C. Yang, H.P. Feng, Y.C. Lin, Titanium surface modified by hydroxyapatite coating for dental implants, Surf. Coat. Technol. 231 (2013) 337-345, https://doi.org/10.1016/j.surfcoat.2012.03.037.

[44] S. Hansson, K.N. Hansson, The effect of limited lateral resolution in the measurement of implant surface roughness: a computer simulation, J. Biomed. Mater. Res. Part A: Off. J. Soc. Biomater. Jpn. Soc. Biomater. Aust. Soc. Biomater. Korean Soc. Biomater. (2005) 2-7, https://doi.org/10.1002/jbm.a.30455.

[45] C. Simitzi, A. Ranella, E. Stratakis, Controlling the morphology and outgrowth of nerve and neuroglial cells: the effect of surface topography, Acta Biomater. 51 (2017) 21-52, https://doi.org/10.1016/j.actbio.2017.01.023

[46] C. Simitzi, K. Karali, A. Ranella, E. Stratakis, Controlling the outgrowth and functions of neural stem cells: the effect of surface topography, ChemPhysChem. 19 (2018) 1143-1163, https://doi.org/10.1002/cphc.201701175.

[47] A.V. Meleshina, E.I. Cherkasova, M.V. Shirmanova, N.V. Klementieva, E. V. Kiseleva, L.B. Snopova, N.N. Prodanets, E.V. Zagaynova, Influence of mesenchymal stem cells on metastasis development in mice in vivo, Stem Cell Res. Ther. 6 (2015) 1-10, https://doi.org/10.1186/s13287-015-0003-7.

[48] A. Nakamura, Y. Dohi, M. Akahane, H. Ohgushi, H. Nakajima, H. Funaoka, Y. Takakura, Osteocalcin secretion as an early marker of osteogenic differentiation of rat mesenchymal stem cells, Tissue Eng. - Part C Methods 15 (2009) 169-180, https://doi.org/10.1089/ten.tec.2007.0334.

[49] C. Granéli, A. Thorfve, U. Ruetschi, H. Brisby, P. Thomsen, A. Lindahl, C. Karlsson, Novel markers of osteogenic and adipogenic differentiation of human bone marrow stromal cells identified using a quantitative proteomics approach, Stem Cell Res. 12 (2014) 153-165, https://doi.org/10.1016/j.scr.2013.09.009.

[50] A.A. Morozov, Reverse particle flux during pulsed laser ablation, Monography (2003) 1-38.

[51] T. Ishizaki, N. Saito, O. Takai, Correlation of cell adhesive behaviors on superhydrophobic, superhydrophilic, and micropatterned superhydrophobic/ superhydrophilic surfaces to their surface chemistry, Langmuir 26 (2010) 8147-8154, https://doi.org/10.1021/la904447c.

[52] P. Taylor, S.M. Oliveira, J.F. Mano, Cell interactions with superhydrophilic and superhydrophobic surfaces, J. Adhes. Sci. (2012) 37-41, https://doi.org/10.1080/ 01694243.2012.697776.

[53] D.-W. Kim, N. Enomoto, Z. Nakagawa, K. Kawamura, Molecular dynamic simulation in titanium dioxide polymorphs: rutile, brookite, and anatase, J. Am. Ceram. Soc. 79 (1996) 1095-1099, https://doi.org/10.1111/j.1151-2916.1996. tb08553.x.

[54] A.N. Christensen, E.K. Andersen, I.G.K. Andersen, O. Dahl, M. Nielsen, M. S. Lehmann, T. Tokii, A neutron diffraction investigation on single crystals of titanium oxide, zirconium carbide, and hafnium nitride, Acta Chem. Scand. 44 (1990) 851-852, https://doi.org/10.3891/acta.chem.scand.44-0851.

[55] E.I. Ageev, Y.M. Andreeva, Y.Y. Karlagina, Y.R. Kolobov, S.S. Manokhin, G. V. Odintsova, A.A. Slobodov, V.P. Veiko, Composition analysis of oxide films formed on titanium surface under pulsed laser action by method of chemical thermodynamics, Laser Phys. 27 (2017), https://doi.org/10.1088/1555-6611/ aa5c11.

[56] N.N. Nikitenkov, E.S. Kiselyova, M.E. Konischev, V.S. Sypchenko, A.N. Nikitenkov, V.F. Pichugin, I.A. Shylepov, M. Epple, Investigation of the structure, elemental and phase composition of coatings on the basis of oxynitride titanium deposited by reactive magnetron sputtering, J. Surf. Investig. 8 (2014) 1230-1234, https://doi. org/10.1134/S1027451014060391. 
[57] B.S. Kopf, S. Ruch, S. Berner, N.D. Spencer, K. Maniura-Weber, The role of nanostructures and hydrophilicity in osseointegration: In-vitro protein-adsorption and blood-interaction studies, J. Biomed. Mater. Res. - Part A 103 (2015) 2661-2672, https://doi.org/10.1002/jbm.a.35401.

[58] R. Murugan, S. Ramakrishna, Nano-featured scaffolds for tissue engineering: a review of spinning methodologies, Tissue Eng. 12 (2006) 435-447, https://doi org/10.1089/ten.2006.12.435.

[59] K. Anselme, C. Ffrench-Constant, K.A. DeMali, K. Burridge, Osteoblast adhesion on biomaterials, Myelin Biol. Disord. 1 (2003) 667-681, https://doi.org/10.1242/ jcs.00605.
[60] E.H.J. Danen, A. Sonnenberg, Integrins in regulation of tissue development and function, J. Pathol. 200 (2003) 471-480, https://doi.org/10.1002/path.1416.

[61] A.D. Bershadsky, J.M. Vasiliev, Cytoskeleton, Springer Science \& Business Media, 2012.

[62] K.A. DeMali, K. Burridge, Coupling membrane protrusion and cell adhesion, J. Cell Sci. 116 (2003) 2389-2397, https://doi.org/10.1242/jcs.00605.

[63] R.O. Hynes, Integrins: bidirectional, allosteric signaling machines, Myelin Biol. Disord. 1 (2003) 609-632, https://doi.org/10.1016/B978-012439510-7/50078-4. 